Article

\title{
Comparison of Aerosol Reflectance Correction Schemes Using Two Near-Infrared Wavelengths for Ocean Color Data Processing
}

\author{
Jae-Hyun Ahn ${ }^{1}$, , Young-Je Park ${ }^{1, *}$ and Hajime Fukushima ${ }^{2}$ \\ 1 Korea Institute of Ocean Science and Technology, Korea Ocean Satellite Center, Busan 49111, Korea; \\ brtnt@kiost.ac.kr \\ 2 Tokai University, Hiratsuka 259-1292, Japan; hajime@keyaki.cc.u-tokai.ac.jp \\ * Correspondence: youngjepark@kiost.ac.kr; Tel.: +82-51-664-3002
}

Received: 17 September 2018; Accepted: 8 November 2018; Published: 12 November 2018

\begin{abstract}
This paper reanalyzes the aerosol reflectance correction schemes employed by major ocean color missions. The utilization of two near-infrared (NIR) bands to estimate aerosol reflectance in visible wavelengths has been widely adopted, for example by SeaWiFS/MODIS/VIIRS (GW1994), OCTS/GLI/SGLI (F1998), MERIS/OLCI (AM1999), and GOCI/GOCI-II (A2016). The F1998, AM1999, and A2016 schemes were developed based on GW1994; however, they are implemented differently in terms of aerosol model selection and weighting factor computation. The F1998 scheme determines the contribution of the most appropriate aerosol models in the aerosol optical thickness domain, whereas the GW1994 scheme focuses on single-scattering reflectance. The AM1999 and A2016 schemes both directly resolve the multiple scattering domain contribution. However, A2016 also considers the spectrally dependent weighting factor, whereas AM1999 calculates the spectrally invariant weighting factor. Additionally, ocean color measurements on a geostationary platform, such as GOCI, require more accurate aerosol correction schemes because the measurements are made over a large range of solar zenith angles which causes diurnal instabilities in the atmospheric correction. Herein, the four correction schemes were tested with simulated top-of-atmosphere radiances generated by radiative transfer simulations for three aerosol models. For comparison, look-up tables and test data were generated using the same radiative transfer simulation code. All schemes showed acceptable accuracy, with less than $10 \%$ median error in water reflectance retrieval at $443 \mathrm{~nm}$. Notably, the accuracy of the A2016 scheme was similar among different aerosol models, whereas the other schemes tended to provide better accuracy with coarse aerosol models than the fine aerosol models.
\end{abstract}

Keywords: atmospheric correction; ocean color; remote sensing; radiative transfer

\section{Introduction}

In the last few decades, ocean observations using visible (VIS) to near-infrared (NIR) wavelength satellite imagery have successfully retrieved oceanic environmental information over a large spatial and temporal range [1-8]. Atmospheric correction is a primary process in satellite ocean color missions, in which surface water reflectance, $\rho_{w n}$, is extracted from the top of atmosphere (TOA). The quantity of $\rho_{w n}$ is generally less than $10 \%$ of the TOA reflectance $\left(\rho_{\text {TOA }}\right)$; thus, atmospheric reflectance and transmittance should be computed as accurately as possible. Ignoring the surface-reflectance from sun-glint and whitecaps, $\rho_{\text {TOA }}$ at each wavelength $(\lambda)$ can be described as follows $[9,10]$ :

$$
\rho_{\mathrm{TOA}}=\rho_{r}+\rho_{a}+\rho_{r a}+t_{d}^{s} t_{d}^{v} \rho_{w n}
$$


where $\rho_{r}$ is the Rayleigh multiple-scattering (molecular multiple-scattering) reflectance in the absence of aerosols, and $\rho_{a}+\rho_{r a}$ is the aerosol multiple-scattering reflectance in the presence of air molecules (denoted $\rho_{a m}$ ). Terms $t^{s}{ }_{d}$ and $t^{v}{ }_{d}$ are the diffuse transmittances of the atmosphere from the sun to the sea surface and from the sea surface to the sensor, respectively.

Traditional atmospheric correction processes first compute $\rho_{r}(\lambda)$ within $1 \%$ error using a radiative transfer simulation [11-15]. Following subtraction of the Rayleigh reflectance contribution, $\rho_{a m}(\mathrm{NIR})$ can be estimated by assuming that the NIR water-leaving reflectance is negligible, i.e., $\rho_{w n}(\mathrm{NIR})=0$, due to the relatively strong light absorption of the waterbody or so-called "black pixel" assumption. $\rho_{a m}(\mathrm{VIS})$ is then extrapolated from satellite-observed $\rho_{a m}(\mathrm{NIR})$ by inversion of the radiative transfer simulation.

The inverse processes for aerosol correction are generally separated into two steps: aerosol model selection, and subsequent spectral extrapolation of $\rho_{a m}$ (VIS) from $\rho_{a m}$ (NIR). In the model selection step, two similar aerosol models, and the contributions of their weighting factors, are extrapolated from $\rho_{a m}(\mathrm{NIR}) . \rho_{a m}(\mathrm{VIS})$ is then computed from $\rho_{a m}(\mathrm{NIR})$ using the aerosol information estimated in the extrapolation step.

Various inverse schemes using two-NIR bands have been developed for ocean color missions, including the SeaWiFS/MODIS/VIIRS scheme [9,10] (denoted GW1994), OCTS/GLI/SGLI scheme [16,17] (denoted F1998), MERIS/OLCI scheme [18,19] (denoted AM1999), and GOCI/GOCI-II scheme [20] (denoted A2016). Schemes F1998, AM1999, and A2016 were developed theoretically based on GW1994 and the aerosol model selection and spectral extrapolation are slightly different.

Schemes GW1994, F1998, and AM1999, but not A2016, were compared and evaluated for a coarse maritime aerosol model with a relative humidity (RH) of $80 \%$, and presented in a report by the International Ocean Colour Coordinating Group (IOCCG) [21]. However, the IOCCG comparison focused more on differences in atmospheric correction systems than on differences of the aerosol correction schemes. Since each scheme used different aerosol models and different radiative transfer code and different Mie scattering code, it is difficult to determine which factors account for the different performances between the schemes.

In this paper, we first revisit and compare the above-mentioned schemes, including the A2016 scheme, and then present our results, in which the performance of each algorithm was examined using a simulated TOA dataset generated by radiative transfer simulations [22-24]. Our analysis was performed using aerosol models with a size distribution including fine to coarse aerosols, whereas the IOCCG study only looked at coarse aerosols in their models. For clarification of the comparison, we used the same code and model for the radiative transfer, Mie scattering calculations, and aerosol models for both the implementation and the analysis result.

\section{The Two-NIR Aerosol Correction Methods Used by the Various Schemes}

This section describes various two-NIR aerosol correction schemes. The correction schemes and look-up tables were developed simultaneously to allow comparison (as summarized in Table 1). Fundamentally, F1998, AM1999, and A2016 were developed based on GW1994; the principle differences between the listed schemes lie in the details of the aerosol model and weighting factor determination. Specifically, the GW1994 scheme uses the spectral ratio of the aerosol single-scattering reflectance of two NIR bands, and the F1998 scheme uses the spectral ratio of the aerosol optical thickness $\left(\tau_{a}\right)$ of two NIR bands\}. Both the AM1999 and A2016 schemes apply the spectral ratio of aerosol multiple-scattering reflectance of two NIR bands; however, A2016 is slightly modified to consider the spectrally varying weighting factor $[19,20]$. In the AM1999 scheme, the path reflectance increment ratio term $\left(\rho_{a m}+\rho_{r}\right) / \rho_{r}$ by aerosol concentration is utilized, whereas other schemes use $\rho_{a m}$. 
Table 1. Aerosol reflectance correction schemes based on the black pixel assumption.

\begin{tabular}{cccc}
\hline Method & References & Applied Sensors & Aerosol Model Selection Domain \\
\hline GW1994 & {$[9,10]$} & SeaWiFS, MODIS, VIIRS & Single-scattering \\
F1998 & {$[16,17]$} & OCTS, GLI, SGLI & Aerosol optical thickness \\
AM1999 & {$[18,19]$} & MERIS, OLCI & Multiple-scattering \\
A2016 & {$[20]$} & GOCI, GOCI-II & Multiple-scattering \\
\hline
\end{tabular}

\subsection{GW1994 Scheme}

The GW1994 scheme determines aerosol model contributions in the single-scattering domain. Therefore, GW1994 first converts $\rho_{a m}$ into single-scattering aerosol reflectance $\left(\rho_{a s}\right)$ for two NIR bands (hereafter, the shorter wavelength NIR band is denoted by NIRs, and the longer wavelength NIR band is denoted by $\mathrm{NIR}_{\mathrm{L}}$ ) for all $i$-th candidate aerosol models $\left(M_{i}\right)$, as follows:

$$
\rho_{a s}\left(M_{i}, \lambda, \Theta\right)=F_{m \rightarrow s}\left(\rho_{a m}, M_{i}, \lambda, \Theta\right)
$$

where $F_{m \rightarrow s}$ is the empirical function for converting $\rho_{a s}$ to $\rho_{a m}$ for specific $\lambda, M_{i}$, and $\Theta$. The $\Theta$ is the scanning geometry variable that is a combination of solar zenith angle, satellite zenith angle, and relative azimuth angle values $[9,10,21,25]$.

$\rho_{a s}$ values are then used to calculate the single-scattering reflectance ratio $\left(\varepsilon_{a s}\right)$, used for selecting the appropriate aerosol models from among the candidate models $\left(M_{i}\right)$ :

$$
\varepsilon_{a s}\left(M_{i}, \mathrm{NIR}_{\mathrm{S}}, \mathrm{NIR}_{\mathrm{L}}, \Theta\right)=\rho_{a s}\left(M_{i}, \mathrm{NIR}_{\mathrm{S}}, \Theta\right) / \rho_{a s}\left(M_{i}, \mathrm{NIR}_{\mathrm{L}}, \Theta\right)
$$

Each $M_{i}$ has a theoretical eigenvalue of $\varepsilon_{a s}$ (denoted as $\varepsilon^{\mathrm{M}}{ }_{a s}$ ) derived from the analytical single-scattering reflectance model, determined by the single-scattering albedo of $M_{i}$ and the phase function. The GW1994 scheme selects two similar aerosol models, $M_{\mathrm{L}}$ and $M_{\mathrm{H}}$, by comparing the representative $\varepsilon_{a s}$ (denoted as $\varepsilon^{r}$ as $)$ to $\varepsilon^{\mathrm{M}}$ as, as follows:

$$
\varepsilon_{a s}^{\mathrm{M}}\left(M_{\mathrm{L}}, \mathrm{NIR}_{\mathrm{S}}, \mathrm{NIR}_{\mathrm{L}}, \Theta\right) \leq \varepsilon_{a s}^{r}\left(\mathrm{NIR}_{\mathrm{S}}, \mathrm{NIR}_{\mathrm{L}}, \Theta\right)<\varepsilon_{a s}^{\mathrm{M}}\left(M_{\mathrm{H}}, \mathrm{NIR}_{\mathrm{S}}, \mathrm{NIR}_{\mathrm{L}}, \Theta\right)
$$

The representative $\varepsilon_{a s}\left(\mathrm{NIR}_{\mathrm{S}}, \mathrm{NIR}_{\mathrm{L}}\right)$ can be approximated by averaging over the $\varepsilon^{\mathrm{M}}$ as of all candidate models, as the conversion function $F_{m \rightarrow s}$ is less sensitive to the aerosol model for NIR wavelengths:

$$
\varepsilon_{a s}^{r}\left(\mathrm{NIR}_{\mathrm{S}}, \mathrm{NIR}_{\mathrm{L}}, \Theta\right) \approx \frac{1}{N} \sum_{i=1}^{N} \varepsilon_{a s}\left(M_{i}, N I R_{\mathrm{S}}, N I R_{\mathrm{L}}, \Theta\right)
$$

Then, the weighting factors $w^{M_{\mathrm{L}}}$ and $w^{M_{\mathrm{H}}}$ for the two selected aerosols $\left(M_{\mathrm{L}}\right.$ and $\left.M_{\mathrm{H}}\right)$ can be estimated by the fraction of the linear distance between $\varepsilon^{r}$ as and $\varepsilon^{\mathrm{M}}{ }_{a s}$ :

$$
\begin{gathered}
w^{M_{\mathrm{H}}}=\frac{\varepsilon_{a s}^{r}\left(\mathrm{NIR}_{\mathrm{S}}, \mathrm{NIR}_{\mathrm{L}}, \Theta\right)-\varepsilon_{a s}^{\mathrm{M}}\left(M_{\mathrm{L}}, \mathrm{NIR}_{\mathrm{S}}, \mathrm{NIR}_{\mathrm{L}}, \Theta\right)}{\varepsilon_{a s}^{\mathrm{M}}\left(M_{\mathrm{H}}, \mathrm{NIR}_{\mathrm{S}}, \mathrm{NIR}_{\mathrm{L}}, \Theta\right)-\varepsilon_{a s}^{\mathrm{M}}\left(M_{\mathrm{L}}, \mathrm{NIR}_{\mathrm{S}}, \mathrm{NIR}_{\mathrm{L}}, \Theta\right)}, \\
w^{M_{\mathrm{L}}}=1-w^{M_{\mathrm{H}}}
\end{gathered}
$$

The $\rho_{a s}(\mathrm{VIS})$ for the two selected models can be extrapolated spectrally from $\rho_{a s}(\mathrm{NIR})$ based on $\varepsilon^{\mathrm{M}}{ }_{a s}(\mathrm{NIR}, \mathrm{VIS})$. Having derived the values $w^{M_{\mathrm{L}}}$ and $w^{M_{\mathrm{H}}}$ for $M_{\mathrm{L}}$ and $M_{\mathrm{H}}$, respectively, the aerosol multiple-scattering reflectance $\left(\rho_{a m}\right)$ in the VIS bands is given by:

$$
\rho_{a m}(\lambda, \Theta)=w^{M_{\mathrm{L}}} F_{s \rightarrow m}\left(\rho_{a s}, M_{\mathrm{L}}, \lambda, \Theta\right)+w^{M_{\mathrm{H}}} F_{s \rightarrow m}\left(\rho_{a s}, M_{\mathrm{H}}, \lambda, \Theta\right)
$$

where $F_{s \rightarrow m}$ is the inverse function of $F_{m \rightarrow s}[9,10,21,25]$. 


\subsection{F1998 Scheme}

The F1998 scheme determines the contributions of the aerosol models to the $\tau_{a}$ domain [16], and has the advantage that the model-wise single-scattering reflectance ratios are often unevenly distributed over the single-scattering space [26]. For model determination, F1998 uses the inter-band $\tau_{a}$ ratio of two NIR bands, as follows:

$$
\varepsilon_{\tau a}\left(M_{i}, \mathrm{NIR}_{\mathrm{S}}, \mathrm{NIR}_{\mathrm{L}}\right)=\tau_{a}\left(M_{i}, \mathrm{NIR}_{\mathrm{S}}\right) / \tau_{a}\left(M_{i}, \mathrm{NIR}_{\mathrm{L}}\right)
$$

where $\varepsilon_{\tau a}$ is the ratio of $\tau_{a}$ of two wavelengths.

Therefore, the F1998 scheme first converts $\rho_{a m}$ into $\tau_{a}$ for all candidate models, $M_{i}$, using an empirical conversion function $\left(F_{m \rightarrow \tau}\right)$ between $\rho_{a m}$ and $\tau_{a}$, in contrast to Equation (2), as follows:

$$
\tau_{a}\left(M_{i}, \lambda\right)=F_{m \rightarrow \tau}\left(\rho_{a m}, M_{i}, \lambda, \Theta\right)
$$

The $F_{m \rightarrow \tau}$ function can be expressed in several ways $[18,19,27,28]$, and F1998 uses a third-order polynomial function to describe the empirical relationship [16].

Theoretically, each $M_{i}$ has a scan geometry-independent eigenvalue of $\varepsilon^{\mathrm{M}}{ }_{\tau a}$ that can be expressed by the ratio of the aerosol extinction coefficient $K_{\text {ext }}\left(M_{i}, \lambda\right)$, as follows:

$$
\varepsilon_{\tau a}^{\mathrm{M}}\left(M_{i}, \lambda_{1}, \lambda_{2}\right)=\frac{K_{e x t}\left(M_{i}, \lambda_{1}\right)}{K_{e x t}\left(M_{i}, \lambda_{2}\right)}
$$

In a similar way to Equation (4), the contributions of $M_{\mathrm{L}}$ and $M_{\mathrm{H}}$ can be determined by comparing the representative $\varepsilon_{\tau a}$ (denoted as $\varepsilon^{r} \tau a$ ) to $\varepsilon^{\mathrm{M}}{ }_{\tau a}$, as follows:

$$
\varepsilon_{\tau a}^{\mathrm{M}}\left(M_{\mathrm{L}}, \mathrm{NIR}_{\mathrm{S}}, \mathrm{NIR}_{\mathrm{L}}\right) \leq \varepsilon_{\tau a}^{r}\left(\mathrm{NIR}_{\mathrm{S}}, \mathrm{NIR}_{\mathrm{L}}\right)<\varepsilon_{\tau a}^{\mathrm{M}}\left(M_{\mathrm{H}}, \mathrm{NIR}_{\mathrm{S}}, \mathrm{NIR}_{\mathrm{L}}\right)
$$

To enhance the accuracy in determining the two aerosol models $\left(M_{\mathrm{H}}\right.$ and $\left.M_{\mathrm{L}}\right)$ and their corresponding weighting factors $\left(w^{M_{\mathrm{L}}}\right.$ and $\left.w^{M_{\mathrm{H}}}\right)$, the F1998 scheme uses a weighted-average value of $\varepsilon_{\tau a}$ for all $M_{i}$ :

$$
\begin{gathered}
\varepsilon_{\tau a}^{r}\left(\mathrm{NIR}_{\mathrm{S}}, \mathrm{NIR}_{\mathrm{L}}\right)=\frac{\sum_{i=1}^{N} \gamma_{i} \varepsilon_{\tau a}\left(M_{i}, \mathrm{NIR} R_{\mathrm{S}}, \mathrm{NIR} R_{\mathrm{L}}\right)}{\sum_{i=1}^{N} \gamma_{i}} \\
\gamma_{i}(\lambda)=\frac{1}{\left|\varepsilon_{\tau a}\left(M_{i}, \mathrm{NIR}_{\mathrm{S}}, \mathrm{NIR}_{\mathrm{L}}\right)-\varepsilon_{\tau a}^{\mathrm{M}}\left(M_{\mathrm{L}}, \mathrm{NIR}_{\mathrm{S}}, \mathrm{NIR}_{\mathrm{L}}\right)\right|} \\
w^{M_{\mathrm{H}}}=\frac{\varepsilon_{\tau a}^{r}\left(\mathrm{NIR}_{\mathrm{S}}, \mathrm{NIR}_{\mathrm{L}}\right)-\varepsilon_{\tau a}\left(M_{\mathrm{L}}, \mathrm{NIR}_{\mathrm{S}}, \mathrm{NIR}_{\mathrm{L}}\right)}{\varepsilon_{\tau a}\left(M_{\mathrm{H}}, \mathrm{NIR}_{\mathrm{S}}, \mathrm{NIR}_{\mathrm{L}}\right)-\varepsilon_{\tau a}\left(M_{\mathrm{L}}, \mathrm{NIR}_{\mathrm{S}}, \mathrm{NIR}_{\mathrm{L}}\right)} \\
w^{M_{\mathrm{L}}}=1-w^{M_{\mathrm{H}}}
\end{gathered}
$$

In the last step, $\rho_{a m}$ for all VIS bands can be computed similarly to Equation (8), as follows:

$$
\begin{gathered}
\rho_{a m}(\lambda, \Theta)=w^{M_{\mathrm{L}}} F_{\tau \rightarrow m}\left(\tau_{a}, M_{\mathrm{L}}, \lambda, \Theta\right)+w^{M_{\mathrm{H}}} F_{\tau \rightarrow m}\left(\tau_{a}, M_{\mathrm{H}}, \lambda, \Theta\right) \\
\tau_{a}\left(M_{i}, \lambda_{1}\right)=\tau_{a}\left(M_{i}, \lambda_{2}\right) \frac{K_{e x t}\left(M_{i}, \lambda_{1}\right)}{K_{\text {ext }}\left(M_{i}, \lambda_{2}\right)}
\end{gathered}
$$

where $F_{\tau \rightarrow m}$ is the inverse function of $F_{m \rightarrow \tau}$ [16].

\subsection{AM1999 Scheme}

In the AM1999 scheme, the atmospheric path reflectance ratio to Rayleigh reflectance $\left(\rho_{\chi}\right)$ is used for the aerosol estimation, whereas other general aerosol correction schemes compute $\rho_{r}$ and $\rho_{a m}$ separately, as follows: 


$$
\rho_{\chi}(\lambda)=\frac{\rho_{r}(\lambda)+\rho_{a m}(\lambda)}{\rho_{r}(\lambda)}
$$

According to Antoine and Morel $[18,28], \rho_{\chi}\left(\lambda_{1}\right)$ for $M_{i}$ can be modeled from $\rho_{\chi}\left(\lambda_{2}\right)$ in a similar way to F1998, using a $\rho_{\chi}$ versus $\tau_{a}$ relationship in which Equation (10) and (18) takes the following form:

$$
\begin{gathered}
\tau_{a}\left(M_{i}, \lambda\right)=F_{\chi \rightarrow \tau}\left(\rho_{\chi}, M_{i}, \lambda, \Theta\right) \\
\rho_{\chi}^{M}\left(M_{i}, \lambda, \Theta\right)=F_{\tau \rightarrow \chi}\left(\tau_{a}, M_{i}, \lambda, \Theta\right)
\end{gathered}
$$

where $F_{\chi \rightarrow \tau}$ is the conversion function from $\rho_{\chi}$ to $\tau_{a}$, expressed as a quadratic equation, and $F_{\tau \rightarrow \chi}$ is the inverse function of $F_{\chi \rightarrow \tau}[18,19,28]$. The value $\rho^{M}{ }_{\chi}$ is the modeled $\rho_{\chi}$ for candidate model $M_{i}$.

To select the two-closest aerosol models and determine the corresponding weighting factor, $\rho_{\chi}\left(\mathrm{NIR}_{\mathrm{S}}\right)$ for all candidate aerosol models $\rho^{M}{ }_{\chi}\left(M_{i}, \mathrm{NIR}_{\mathrm{S}}\right)$ are first computed using a quadratic expression describing the relationship of $\rho_{\chi}$ with $\tau_{a}$ and $K_{\text {ext }}\left(M_{i}, \lambda\right)$ [28]. Then, $M_{\mathrm{L}}$ and $M_{\mathrm{H}}$ are selected by comparing $\rho_{\chi}(\mathrm{NIR})$ observed by satellite to the $\rho^{M}{ }_{\chi}\left(M_{i}\right.$, NIRS $)$ of all candidate models, as follows:

$$
\rho_{\chi}^{M}\left(M_{\mathrm{L}}, \mathrm{NIR}_{\mathrm{S}}, \Theta\right)<\rho_{\chi}\left(\mathrm{NIR}_{\mathrm{S}}, \Theta\right) \leq \rho_{\chi}^{M}\left(M_{\mathrm{H}}, \mathrm{NIR}_{\mathrm{S}}, \Theta\right)
$$

The mixing ratio $w^{M_{\mathrm{H}}}$ is then derived directly in the multiple-scattering domain:

$$
\begin{gathered}
w^{M_{\mathrm{H}}}=\frac{\rho_{\chi}\left(\mathrm{NIR}_{\mathrm{S}}, \Theta\right)-\rho_{\chi}^{M}\left(M_{\mathrm{L}}, \mathrm{NIR}_{\mathrm{S}}, \Theta\right)}{\rho_{\chi}^{M}\left(M_{\mathrm{H}}, \mathrm{NIR}_{\mathrm{S}}, \Theta\right)-\rho_{\chi}^{M}\left(M_{\mathrm{L}}, \mathrm{NIR}_{\mathrm{S}}, \Theta\right)} \\
w^{M_{\mathrm{L}}}=1-w^{M_{\mathrm{H}}}
\end{gathered}
$$

Using the two models $\left(M_{\mathrm{L}}\right.$ and $\left.M_{\mathrm{H}}\right)$ and their derived weighting factors $\left(w^{M_{\mathrm{L}}}\right.$ and $w^{M_{\mathrm{H}}}$, respectively), $\rho_{\chi}$ for all VIS bands can be computed as follows:

$$
\rho_{\chi}(\lambda, \Theta)=w^{M_{\mathrm{L}}} \rho_{\chi}^{M}\left(M_{\mathrm{H}}, \lambda, \Theta\right)+w^{M_{\mathrm{H}}} \rho_{\chi}^{M}\left(M_{\mathrm{H}}, \lambda, \Theta\right)
$$

where $\rho_{\chi}^{M}\left(M_{\mathrm{L}}, \lambda\right)$ and $\rho_{\chi}^{M}\left(M_{\mathrm{H}}, \lambda\right)$ are spectrally extrapolated from $\rho_{\chi}\left(\mathrm{NIR}_{\mathrm{L}}\right)$ [29].

\subsection{A2016 Scheme}

To select the appropriate aerosol models and perform spectral extrapolation of their reflectance from the NIR to VIS bands, the A2016 method directly estimates the reflectance fraction of the two-closest models in the multiple-scattering domain, without considering the single-scattering domain. It uses the spectral relationships between multiple-scattering aerosol reflectance and the different wavelengths expressed by polynomial functions, whereas $\tau_{a}$ changes to $M_{i}, \theta_{v}, \theta_{s}$, and $\phi_{s v}$, according to the following equation:

$$
\rho_{a m}^{M}\left(M_{i}, \lambda_{2}\right)=\sum_{n=1}^{D} c_{n}\left(M_{i}, \lambda_{1}, \lambda_{2}, \Theta\right) \rho_{a m}\left(\lambda_{1}\right)^{n},
$$

where $D$ is the degree of the polynomial (Table 2) and $\rho^{M}{ }_{a m}\left(M_{i}, \lambda\right)$ is the theoretically computed $\rho_{a m}(\lambda)$ for model $M_{i}$, considering the geometries and band pairs. The term $c_{n}$ represents the constants of the polynomial equation for models $M_{i}, \theta_{s}, \theta_{v}$, and $\phi_{s v}$.

Table 2. Degree of the polynomial Equation (26) for Geostationary Ocean Colour Imager (GOCI) wavelengths [20].

\begin{tabular}{cccccccc}
\hline$\lambda_{1}(\mathrm{~nm})$ & 865 & 745 & 745 & 745 & 555 & 555 & 555 \\
$\lambda_{2}(\mathrm{~nm})$ & 745 & 680 & 660 & 555 & 490 & 443 & 412 \\
$D$ & 2 & 3 & 3 & 4 & 4 & 4 & 4 \\
Min. $R^{2}$ & 0.99978 & 0.99995 & 0.99996 & 0.99999 & 0.99994 & 0.99996 & 0.99998 \\
\hline
\end{tabular}


To estimate $\rho_{a m}(\mathrm{VIS})$ using A2016, as explained above, $\rho^{M}{ }_{a m}\left(M_{i}, \mathrm{NIR}_{\mathrm{S}}\right)$ for all candidate aerosol models can be calculated using Equation (26). Then, the most similar models, $M_{\mathrm{L}}$ and $M_{\mathrm{H}}$, can be determined by comparison of the observed $\rho_{a m}\left(\mathrm{NIR}_{\mathrm{S}}\right)$ and $\rho^{M_{a m}}\left(M_{i}, \mathrm{NIR}\right)$ of all candidate models, as follows:

$$
\rho_{a m}^{M}\left(M_{\mathrm{L}}, \mathrm{NIR}_{\mathrm{S}}\right) \leq \rho_{a m}\left(\mathrm{NIR}_{\mathrm{S}}\right)<\rho_{a m}^{M}\left(M_{\mathrm{H}}, \mathrm{NIR}_{\mathrm{S}}\right) .
$$

Therefore, two aerosol models, $M_{\mathrm{L}}$ and $M_{\mathrm{H}}$, contribute to $\rho_{a m}(\mathrm{NIR})$, as described below:

$$
\begin{gathered}
\rho_{a m}\left(\mathrm{NIR}_{\mathrm{L}}\right)=w^{M_{\mathrm{L}}} \rho_{a m}\left(\mathrm{NIR}_{\mathrm{L}}\right)+w^{M_{\mathrm{H}}} \rho_{a m}\left(\mathrm{NIR}_{\mathrm{L}}\right), \\
\rho_{a m}\left(\mathrm{NIR}_{\mathrm{S}}\right)=\sum_{n=1}^{2} c_{n}\left(M_{\mathrm{H}}, \lambda, \Theta\right)\left[w^{M_{\mathrm{H}}} \rho_{a m}\left(N I R_{\mathrm{L}}\right)\right]^{n}+\sum_{n=1}^{2} c_{n}\left(M_{\mathrm{L}}, \lambda, \Theta\right)\left[w^{M_{\mathrm{L}}} \rho_{a m}\left(N I R_{\mathrm{L}}\right)\right]^{n} .
\end{gathered}
$$

The reflectance fraction at NIR $\left(w^{M_{\mathrm{L}}}\right.$ and $\left.w^{M_{\mathrm{H}}}\right)$ can be directly calculated by solving the quadratic formula without any residual errors [20].

Extending Equation (26) by considering the wavelength-dependent reflectance fraction $\left(w^{M_{\mathrm{L}}}\right.$ and $\left.w^{M_{\mathrm{H}}}\right), \rho_{a m}(\mathrm{VIS})$ can be derived as follows:

$$
\begin{aligned}
\rho_{a m}\left(\lambda_{2}\right) & =\sum_{n=1}^{D} c_{n}\left(M_{\mathrm{H}}, \lambda, \Theta\right)\left[w^{M_{\mathrm{H}}} \rho_{a m}^{\mathrm{M}}\left(M_{\mathrm{H}}, \lambda_{1}\right)\right]^{n} \\
& +\sum_{n=1}^{D} c_{n}\left(M_{\mathrm{L}}, \lambda, \Theta\right)\left[w^{M_{\mathrm{L}}} \rho_{a m}^{\mathrm{M}}\left(M_{\mathrm{L}}, \lambda_{1}\right)\right]^{n}
\end{aligned}
$$

\section{Simulation Dataset for the Evaluation}

The four schemes for aerosol multiple-scattering reflectance estimation were evaluated using a simulation dataset generated by a vector radiative transfer code [22-24]. Simulations were carried out for three aerosol models, excluding candidate aerosol models, and 24 scan geometries: $\theta_{s}=0^{\circ}, 25^{\circ}, 50^{\circ}$, and $75^{\circ} ; \theta_{v}=20^{\circ}, 40^{\circ}$, and $60^{\circ}$; and $\phi_{s v}=60^{\circ}$ and $120^{\circ}$. The $\rho_{w n}$ for VIS wavelengths was modeled [29] for chlorophyll-a concentrations of $0.1,0.3$, and $1.0 \mathrm{mg} / \mathrm{m}^{3}$; however, the NIR $\rho_{w n}$ was assumed to be negligible, to satisfy the black pixel assumption [30]. Three aerosol models based on the work of Shettle and Fenn [31] were used for the evaluation: (1) the maritime model, with an RH of $80 \%$ (M80) that represents a coarse-size distribution of aerosol particles; (2) the coastal model, with an RH of $80 \%$ (C80); and (3) the tropospheric model, with an RH of 90\% (T90) to represent a fine-scale aerosol particle distribution [31]. The input parameters for the simulations are summarized in Table 3. We excluded validation data when $\rho_{a m}(865 \mathrm{~nm})$ was greater than 0.027 , based on the cloud masking threshold of the SeaWiFS Data Analysis System (SeaDAS) [32]. To avoid uncertainties arising from the sun-glint effect, cases in which the sun-glint reflectance at the surface exceeded 0.001 were removed.

Table 3. Summary of the input parameters for the simulations.

\begin{tabular}{cc}
\hline Input Parameter & Values \\
\hline Wavelengths & $412,443,490,555,660,680,745,865(\mathrm{~nm})$ \\
Aerosol models & M80, C80, T90 \\
Aerosol optical thicknesses at $865 \mathrm{~nm}$ & $0.03,0.07,0.15,0.25,0.35$ \\
Wind speed at sea surface & $2 \mathrm{~m} / \mathrm{s}$ \\
Solar-zenith angles $\left(\theta_{S}\right)$ & $0^{\circ}, 25^{\circ}, 50^{\circ}, 75^{\circ}$ \\
Viewing zenith angles $\left(\theta_{s}\right)$ & $20^{\circ}, 40^{\circ}, 60^{\circ}$ \\
Relative azimuth angles $\left(\phi_{s v}\right)$ & $60^{\circ}, 120^{\circ}$ \\
Chlorophyll-a concentration & $0.1,0.3,1.0 \mathrm{mg} / \mathrm{m}^{3}$ \\
\hline
\end{tabular}

\section{Results and Discussion}

This section describes the atmospheric correction results and intermediate aerosol parameters over Case-1 waters for the three aerosol models specified, after integrating the four atmospheric correction 
schemes. For quantitative analysis of the four schemes, we used the following statistical parameters: error $(\Delta)$, relative percentage error (RPE), mean absolute percentage error (MAPE), median absolute percentage error (Med.), and root mean square error (RMSE), as follows:

$$
\begin{gathered}
\Delta=v_{n}^{e}-v_{n}^{t} \\
\operatorname{RPE}(\%)=100\left(\frac{\Delta}{v_{n}^{t}}\right) \\
\operatorname{MAPE}(\%)=\frac{1}{K} \sum_{n=1}^{K}|R P E| \\
\operatorname{RMSE}=\sqrt{\frac{1}{n} \sum_{n=1}^{K}\left(\Delta^{2}\right)}
\end{gathered}
$$

where $K$ is the total number of matched pairs, and $v_{n}{ }^{t}$ and $v_{n}{ }^{e}$ are the true and derived values of the $n$th matched entry, respectively.

The analysis was performed after replacing the four aerosol reflectance correction schemes within the atmospheric correction algorithm. The following nine aerosol models were used as candidates for the evaluation: oceanic model with RH 99\% (O99), maritime model with RH 50, 70, 90, and 95\% (M50, M70, M90, and M95, respectively), coastal model with RH 50 and 70\% (C50 and C70, respectively), and tropospheric model with RH 50 and 80\% (T50 and T80, respectively) [31]. We used the same radiative transfer code [22-24] for both the evaluation data and candidate aerosol look-up tables.

The results are summarized as box-and-whisker plots with median, minimum, maximum, and quartile values (Figures 1 and 2). Figure 1a-c shows the errors $(\Delta)$ in aerosol reflectance retrieval at 443,555 , and $660 \mathrm{~nm}$, respectively, for the four schemes. Figure $1 \mathrm{~d}$,e show the errors $(\Delta)$ in $\tau_{a}$ at $865 \mathrm{~nm}$ and the Ångström exponent for $443 \mathrm{~nm}$ relative to $865 \mathrm{~nm}$, respectively. Figure 2a-c show the RPE in $\rho_{w n}$ retrieval at 443,555, and $660 \mathrm{~nm}$, respectively. Table 4 summarizes the statistical results for $\rho_{w n}$ retrieval, for the four schemes and three aerosol types. Note that A2016 uses Equation (10) for retrieval of the $\tau_{a}$ and Ångström exponent, because it does not calculate $\tau_{a}$ itself.

(a)
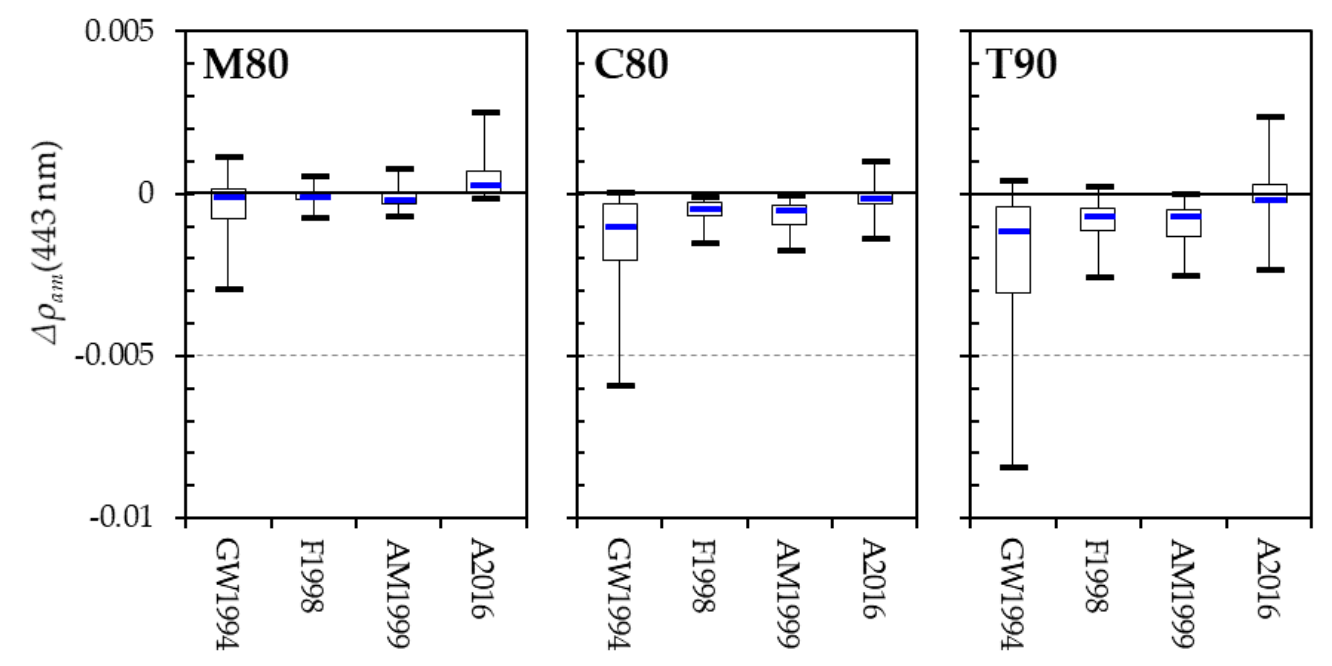

Figure 1. Cont. 
(b)
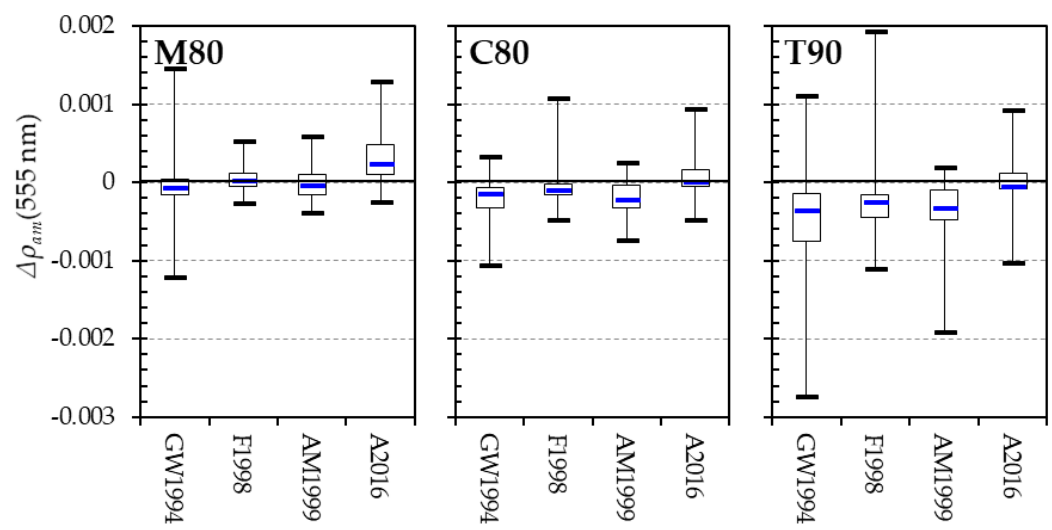

(c)
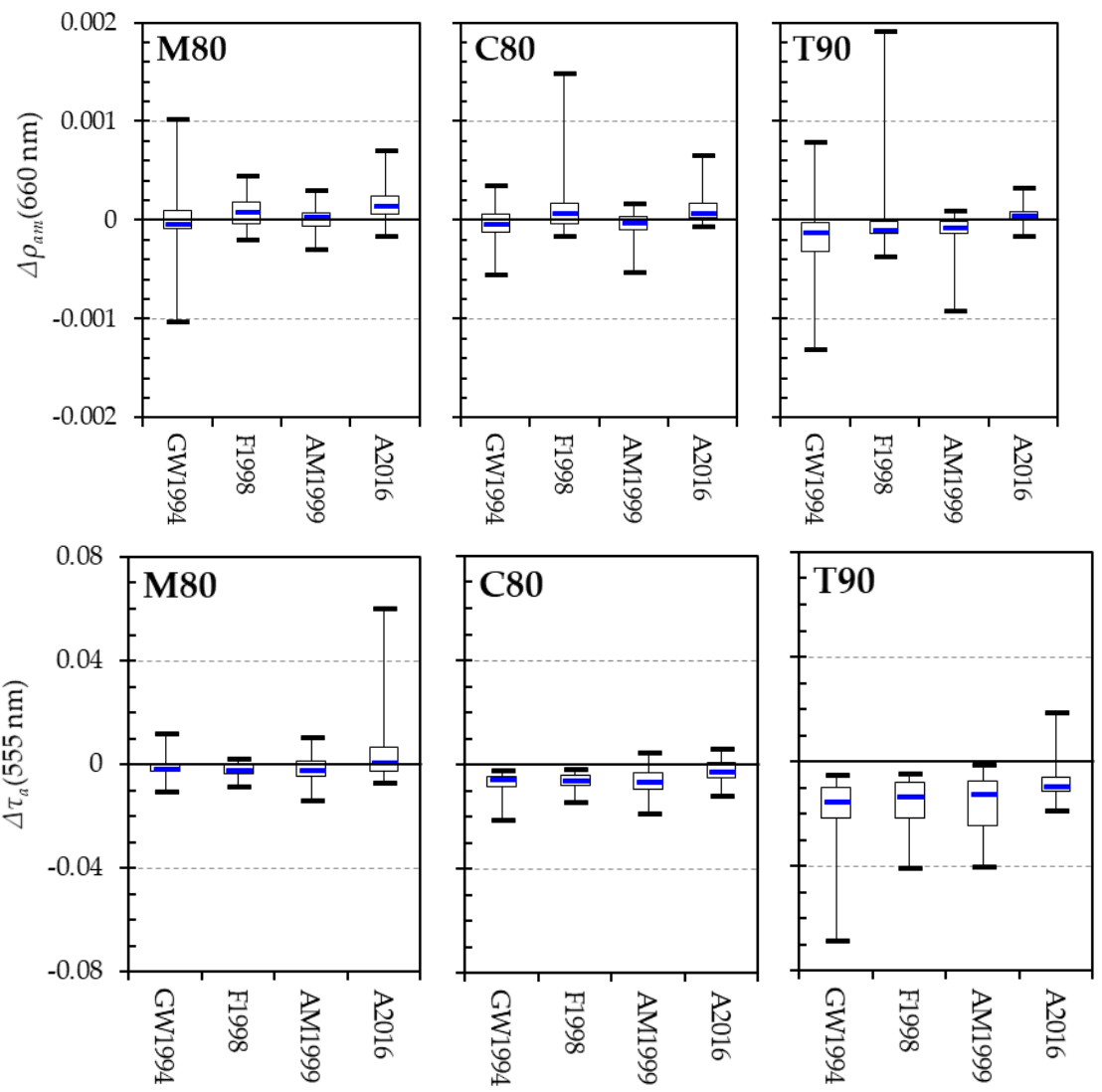

(d)
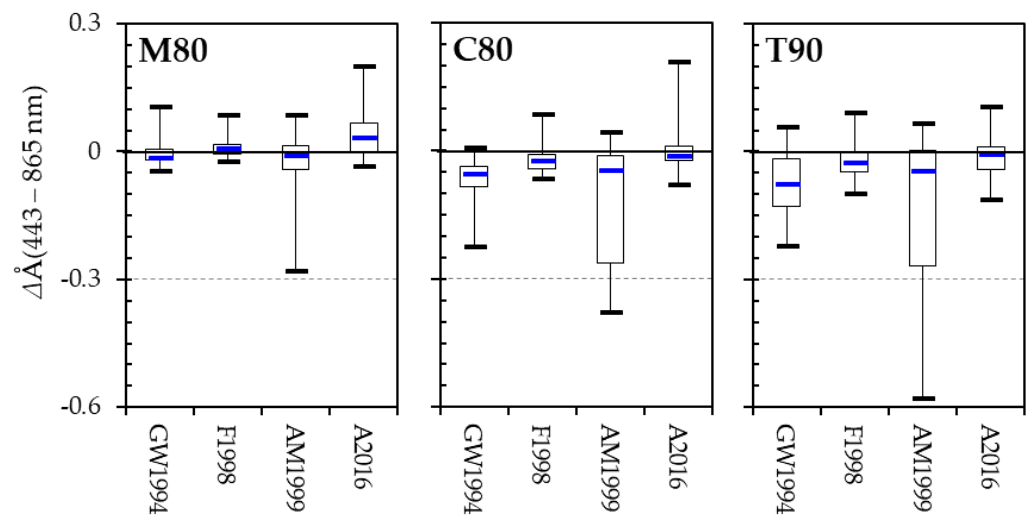

Figure 1. Errors in aerosol retrieval for the four schemes, presented as box-and-whisker plots. Aerosol reflectance differences by scheme for (a) the blue band (443 nm); (b) the green band ( $555 \mathrm{~nm})$; and (c) the red band $(660 \mathrm{~nm})$; (d) aerosol optical thickness difference by scheme for the green band; and (e) aerosol Ångström exponent for $443 \mathrm{~nm}$ relative to $865 \mathrm{~nm}$. 
The median value of $\Delta \rho_{a m}(443 \mathrm{~nm})$ for the four schemes falls between $-0.0011 \sim+0.0007$ (Figure 1). The GW1994, F1998, and AM1999 schemes tend to produce more errors, with underestimation of $\rho_{a m}$ retrieval for T90 aerosol models compared to the other models due to the underestimation of the aerosol optical thickness and Ångström exponent. In the A2016 scheme, on the contrary, $\rho_{a m}$ retrieval errors are more significant, with overestimation for M80 due to the overestimation of aerosol optical thickness and Ångström exponent.

(a)

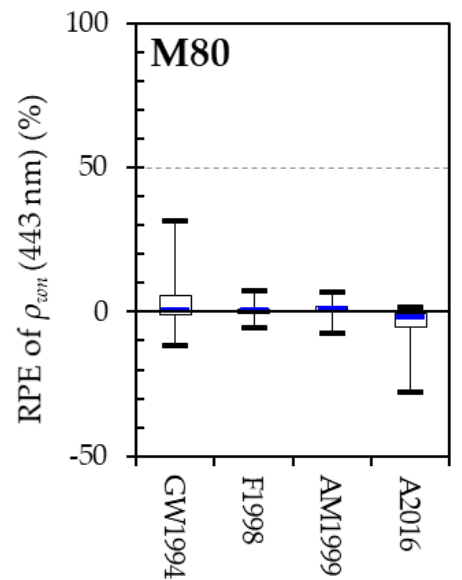

(b)

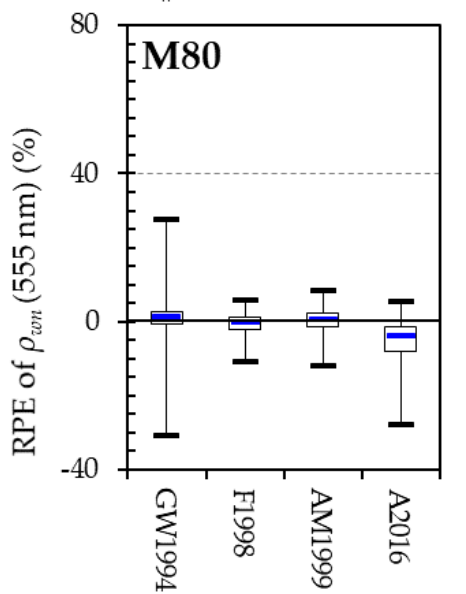

(c)

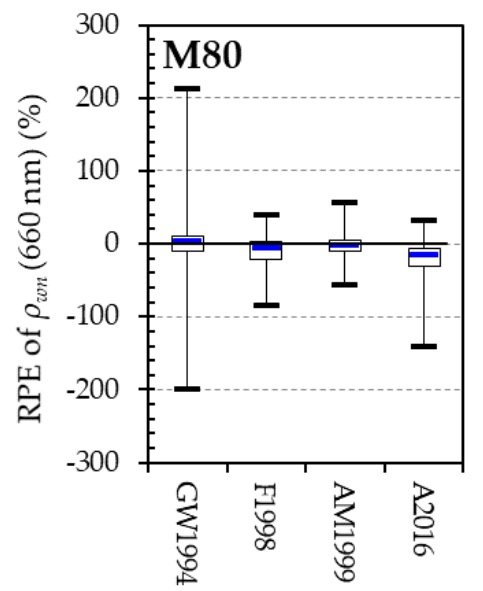

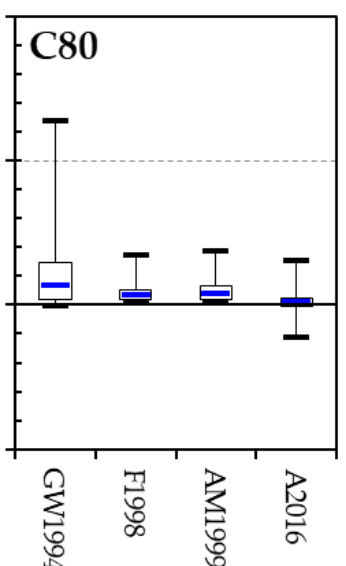
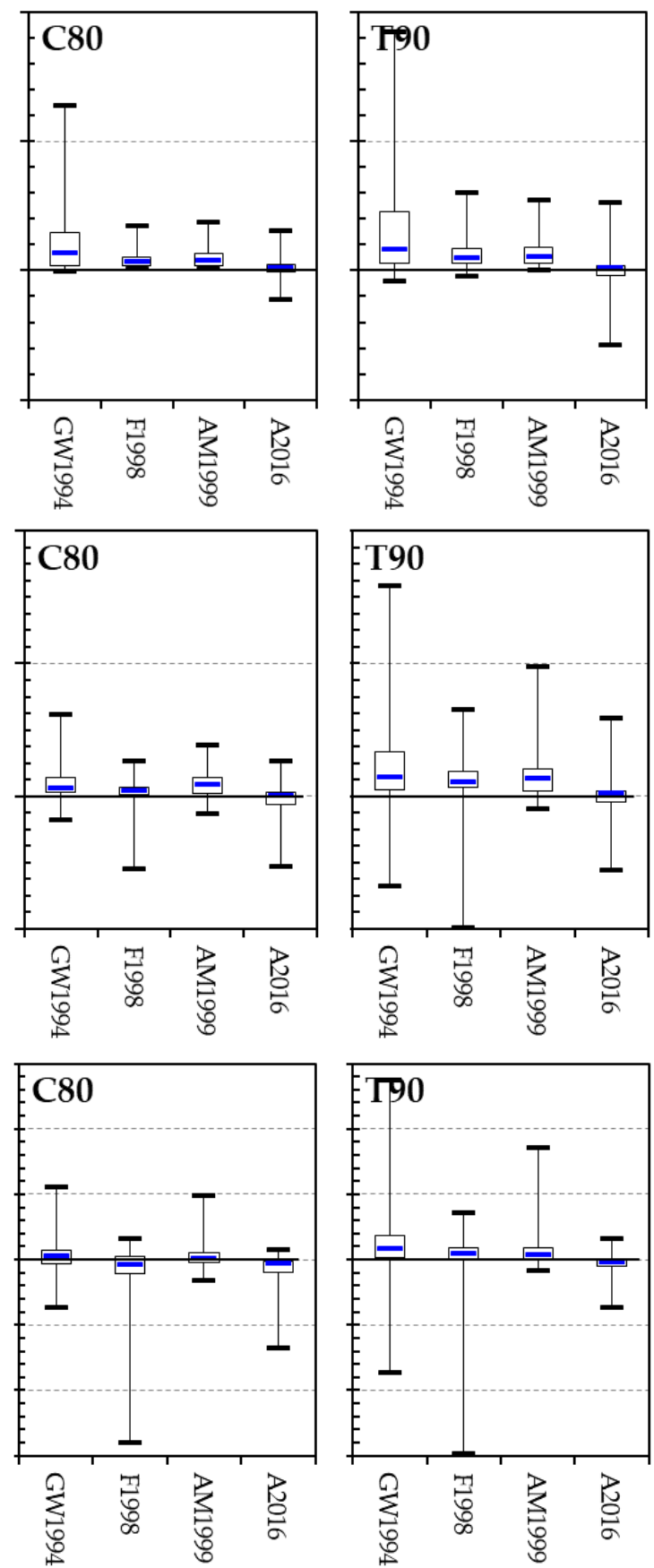

Figure 2. Cont. 
(d)
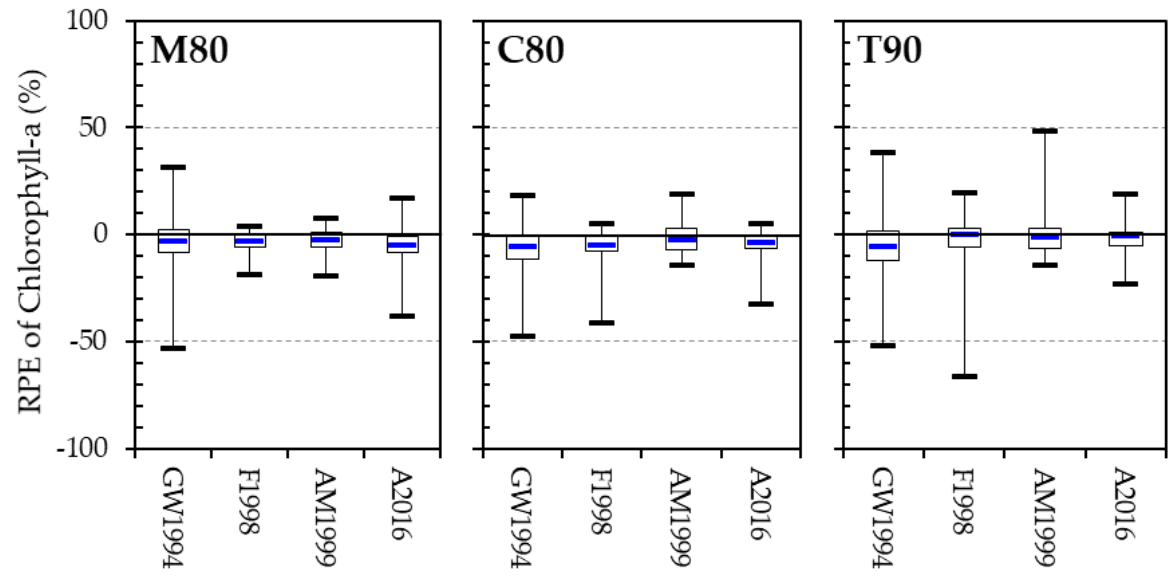

Figure 2. Water reflectance $\left(\rho_{w n}\right)$ retrieval accuracy of the (a) blue; (b) green; and (c) red bands in the atmospheric correction algorithm after integrating the four aerosol correction schemes. Chlorophyll-a estimation error based on OC3 [33] is plotted in (d).

Table 4. Statistical summary of atmospheric correction accuracy.

\begin{tabular}{|c|c|c|c|c|c|c|c|c|c|c|}
\hline & & \multicolumn{3}{|c|}{$\rho_{w n}(443 \mathrm{~nm})$} & \multicolumn{3}{|c|}{$\rho_{w n}(555 \mathrm{~nm})$} & \multicolumn{3}{|c|}{$\rho_{w n}(660 \mathrm{~nm})$} \\
\hline & Method & MAPE & Med. & RMSE & MAPE & Med. & RMSE & MAPE & Med. & RMSE \\
\hline \multirow{4}{*}{ Total } & GW1994 & $10.0 \%$ & $5.1 \%$ & 0.00198 & $6.7 \%$ & $3.5 \%$ & 0.00059 & $27.9 \%$ & $14.4 \%$ & 0.00032 \\
\hline & F1998 & $3.9 \%$ & $2.4 \%$ & 0.00068 & $3.5 \%$ & $2.4 \%$ & 0.00030 & $18.3 \%$ & $12.5 \%$ & 0.00023 \\
\hline & AM1999 & $4.3 \%$ & $2.9 \%$ & 0.00077 & $4.3 \%$ & $3.3 \%$ & 0.00035 & $11.9 \%$ & $8.0 \%$ & 0.00013 \\
\hline & A2016 & $3.4 \%$ & $1.8 \%$ & 0.00067 & $3.9 \%$ & $2.2 \%$ & 0.00034 & $15.6 \%$ & $9.2 \%$ & 0.00017 \\
\hline \multirow{4}{*}{ M80 } & GW1994 & $4.8 \%$ & $2.4 \%$ & 0.00098 & $4.5 \%$ & $2.1 \%$ & 0.00042 & $25.4 \%$ & $10.9 \%$ & 0.00031 \\
\hline & F1998 & $1.2 \%$ & $0.9 \%$ & 0.00021 & $2.0 \%$ & $1.4 \%$ & 0.00016 & $16.5 \%$ & $11.5 \%$ & 0.00016 \\
\hline & AM1999 & $1.8 \%$ & $1.4 \%$ & 0.00031 & $2.6 \%$ & $2.0 \%$ & 0.00021 & $11.2 \%$ & $7.6 \%$ & 0.00012 \\
\hline & A2016 & $4.1 \%$ & $2.0 \%$ & 0.00085 & $5.8 \%$ & $4.0 \%$ & 0.00045 & $22.0 \%$ & $15.4 \%$ & 0.00022 \\
\hline \multirow{4}{*}{$\mathrm{C} 80$} & GW1994 & $10.4 \%$ & $6.4 \%$ & 0.00187 & $4.5 \%$ & $2.6 \%$ & 0.00037 & $18.0 \%$ & $11.5 \%$ & 0.00019 \\
\hline & F1998 & $4.1 \%$ & $3.2 \%$ & 0.00062 & $2.5 \%$ & $1.9 \%$ & 0.00020 & $18.2 \%$ & $11.7 \%$ & 0.00023 \\
\hline & AM1999 & $4.9 \%$ & $3.6 \%$ & 0.00078 & $4.1 \%$ & $3.6 \%$ & 0.00029 & $10.5 \%$ & $7.9 \%$ & 0.00011 \\
\hline & A2016 & $2.7 \%$ & $1.8 \%$ & 0.00046 & $2.8 \%$ & $1.6 \%$ & 0.00024 & $14.5 \%$ & $8.9 \%$ & 0.00016 \\
\hline \multirow{4}{*}{ T90 } & GW1994 & $15.1 \%$ & $8.2 \%$ & 0.00275 & $11.1 \%$ & $7.4 \%$ & 0.00086 & $40.4 \%$ & $22.3 \%$ & 0.00042 \\
\hline & F1998 & $6.5 \%$ & $4.8 \%$ & 0.00099 & $6.1 \%$ & $4.4 \%$ & 0.00046 & $20.4 \%$ & $13.8 \%$ & 0.00028 \\
\hline & AM1999 & $6.5 \%$ & $5.3 \%$ & 0.00104 & $6.3 \%$ & $5.0 \%$ & 0.00048 & $14.1 \%$ & $8.7 \%$ & 0.00017 \\
\hline & A2016 & $3.4 \%$ & $1.8 \%$ & 0.00063 & $3.1 \%$ & $1.6 \%$ & 0.00027 & $9.9 \%$ & $5.7 \%$ & 0.00011 \\
\hline
\end{tabular}

The $\rho_{w n}$ estimation results showed that the atmospheric correction accuracy for the four schemes was acceptable, with median APE values of $\rho_{w n}$ of $<5.1 \%$ and $<3.5 \%$ at $443 \mathrm{~nm}$ and $555 \mathrm{~nm}$, respectively. Although the RMSE of $\rho_{w n}$ at $660 \mathrm{~nm}$ was smaller than that of $\rho_{w n}$ at $443 \mathrm{~nm}$, the MAPE of $\rho_{w n}(660 \mathrm{~nm})$ had a higher value than that of $\rho_{w n}(443 \mathrm{~nm})$, as the $\rho_{w n}$ to aerosol reflectance ratio at $660 \mathrm{~nm}$ is significantly lower than that at $443 \mathrm{~nm}$, due to relatively smaller water reflectance to aerosol reflectance ratio by relatively stronger water absorption at $660 \mathrm{~nm}$. Similar to the aerosol estimation results, the accuracy of the $\rho_{w n}$ estimation for the three schemes GW1994, F1998, and AM1999 improved for the coarse-sized aerosol models, in which aerosol reflectance had less of a multiple-scattering effect. The A2016 scheme showed relatively similar accuracy to the three aerosol models, in which the MAPE ranged from $2.7 \%$ to $4.1 \%$.

\section{Note and Summary}

Two-NIR-band-based aerosol reflectance correction schemes have been widely employed. We implemented and tested four such aerosol correction schemes: SeaWiFS/MODIS/VIIRS (GW1994), OCTS/GLI/SGLI (F1998), MERIS/OLCI (AM1999), and GOCI/GOCI-II (A2016). The GW1994 scheme determines the contribution of the aerosol models in the single-scattering domain after conversion 
from aerosol multiple- to single-scattering reflectance. F1998 determines the contribution to the aerosol optical thickness domain and then uses a weighted average approach to enhance the calculation accuracy of the weighting factors, whereas GW1994 uses an average value. AM1999 determines the contribution in the multiple-scattering domain and then uses linear distance to calculate the weighting factor. There are methods [28,34] that apply an approach similar to that of AM1999 to determine the contribution based on the linear distance of the reflectance in the multiple-scattering domain; these methods are expected to offer comparable performance to that of AM1999. A2016 is similar to AM1999 in terms of selecting aerosol models in the multiple-scattering domain, except that the weighting scheme for A2016 is enhanced to consider the wavelength-dependent weighting factor.

In this study, we intercompared four aerosol correction schemes in an assimilation. However, discrepancies between aerosol models and the actual aerosols can introduce more significant errors than the inaccuracies associated with the inverse scheme. Two-NIR aerosol correction schemes that we evaluated rely on the assumption of non- or less-absorbent aerosol optical properties, although actual aerosols originating from land can absorb more light. Alternative aerosol models are being developed that provide a more realistic representation of the optical properties of aerosols [35]; however, these models are also based on non- or less-absorbent models. All these schemes will significantly underestimate the $\rho_{w n}$ for strongly absorbing aerosols that contain a soot component, as discussed by the IOCCG study [21]. To determine absorbance properties future aerosol correction schemes will require additional aerosol information from other wavelengths, i.e., from the near-ultraviolet regime [17] or from polarization [36]. Errors in variables such as wind speed [37], trace gases [38-41], and air pressure [38] are higher at higher solar and sensor zenith angles. The atmospheric correction accuracy is also impacted by the system vicarious calibration [42-44]. The radiance calibration requirement for atmospheric correction is $<1 \%$. However, the visible calibration gain can be varied by more than $1 \%$ due to different NIR intercalibration. Further work on the NIR calibration is needed to improve this.

The most recent atmospheric correction algorithms yield errors of less than 5\% [2,45], which satisfies the accuracy requirement for ocean colour observations in the open ocean. However, more accurate atmospheric correction algorithms are required to observe diurnal changes from geostationary platforms such as GOCI, since geostationary measurements are made over a wide range of solar zenith angles which significantly increases the atmospheric correction uncertainty. Therefore, further investigation on the error sources from all relevant parameters is needed to improve atmospheric correction algorithms.

Author Contributions: Conceptualization: J.-H.A. and Y.-J.P.; implementation, J.-H.A.; confirming implementation: Y.-J.P. and H.F.; validation: J.-H.A. and Y.-J.P.; formal analysis: Y.-J.P. and J.-H.A.; writing—original draft preparation: J.-H.A.; writing—review and editing: Y.-J.P. and H.F.; project administration: Y.-J.P.; funding acquisition: Y.-J.P.

Funding: This research was funded by Korea Ministry of Oceans and Fisheries (MOF) [PJT200720].

Acknowledgments: This research was supported by the "Development of the integrated data processing system for GOCI-II" funded by the Ministry of Ocean and Fisheries, Korea. The authors are grateful to Mitsuhiro Toratani and Kazunori Ogata for collaboration on GOCI and SGLI atmospheric correction development. Authors would like to thank Cara Wilson for rechecking the grammar and writing of the manuscript.

Conflicts of Interest: The authors declare no conflict of interest.

\section{References}

1. McClain, C.R.; Feldman, G.C.; Hooker, S.B. An overview of the SeaWiFS project and strategies for producing a climate research quality global ocean bio-optical time series. Deep Sea Res. Part II Top. Stud. Oceanogr. 2004, 51, 5-42. [CrossRef]

2. $\quad$ Esaias, W.E.; Abbott, M.R.; Barton, I.; Brown, O.B.; Campbell, J.W.; Carder, K.L.; Clark, D.K.; Evans, R.H.; Hoge, F.E.; Gordon, H.R.; et al. An overview of MODIS capabilities for ocean science observations. IEEE Trans. Geosci. Remote Sens. 1998, 36, 1250-1265. [CrossRef]

3. Kawamura, H.; OCTS Team. OCTS mission overview. J. Oceanogr. 1998, 54, 383-399. [CrossRef] 
4. Rast, M.; Bezy, J.L.; Bruzzi, S. The ESA Medium Resolution Imaging Spectrometer MERIS a review of the instrument and its mission. Int. J. Remote Sens. 1999, 20, 1681-1702. [CrossRef]

5. Tanaka, K.; Kurihara, S.; Okamura, Y. The sensor characterization of global imager (GLI) on ADEOS-II satellite. IEICE Trans. Commun. 2005, J88-B, 151-157.

6. Tanaka, K.; Okamura, Y.; Amano, T.; Hiramatsu, M.; Shiratama, K. Operation concept of the secondgeneration global imager (SGLI). In Earth Observing Missions and Sensors: Development, Implementation, and Characterization. Int. Soc. Opt. Photonics 2010, 7862, 786209.

7. Kang, G.; Coste, P.; Youn, H.; Faure, F.; Choi, S. An in-orbit radiometric calibration method of the geostationary ocean color imager. IEEE Trans. Geosci. Remote Sens. 2010, 48, 4322-4328. [CrossRef]

8. Wang, M.; Liu, X.; Jiang, L.; Son, S.; Sun, J.; Shi, W.; Tan, L.; Naik, P.; Mikelsons, K.; Wang, X.; et al. Evaluation of VIIRS ocean color products. In Ocean Remote Sensing and Monitoring from Space. Int. Soc. Opt. Photonics 2014, 9261, 92610E.

9. Gordon, H.R.; Wang, M. Retrieval of water-leaving radiance and aerosol optical thickness over the oceans with SeaWiFS: A preliminary algorithm. Appl. Opt. 1994, 33, 443-452. [CrossRef] [PubMed]

10. Wang, M.; Gordon, H.R. A simple, moderately accurate, atmospheric correction algorithm for SeaWiFS. Remote Sens. Eviron. 1994, 50, 231-239. [CrossRef]

11. Gordon, H.R.; Brown, J.W.; Evans, R.H. Exact Rayleigh scattering calculations for use with the Nimbus-7 coastal zone color scanner. Appl. Opt. 1988, 27, 862-871. [CrossRef] [PubMed]

12. Gordon, H.R.; Wang, M. Surface-roughness considerations for atmospheric correction of ocean color sensors. 1: The Rayleigh-scattering component. Appl. Opt. 1992, 31, 4247-4260. [CrossRef] [PubMed]

13. Wang, M. The Rayleigh lookup tables for the SeaWiFS data processing: Accounting for the effects of ocean surface roughness. Int. J. Remote Sens. 2002, 23, 2693-2702. [CrossRef]

14. Wang, M. A refinement for the Rayleigh radiance computation with variation of the atmospheric pressure. Int. J. Remote Sens. 2005, 26, 5651-5663. [CrossRef]

15. Wang, M. Rayleigh radiance computations for satellite remote sensing: Accounting for the effect of sensor spectral response function. Opt. Express 2016, 24, 12414-12429. [CrossRef] [PubMed]

16. Fukushima, H.; Higurashi, A.; Mitomi, Y.; Nakajima, T.; Noguchi, T.; Tanaka, T.; Toratani, M. Correction of atmospheric effect on ADEOS/OCTS ocean color data: Algorithm description and evaluation of its performance. J. Oceanogr. 1998, 54, 417-430. [CrossRef]

17. Toratani, M.; Fukushima, H.; Murakami, H.; Tanaka, A. Atmospheric correction scheme for GLI with absorptive aerosol correction. J. Oceanogr. 2007, 63, 525-532. [CrossRef]

18. Antoine, D.; Morel, A. A multiple scattering algorithm for atmospheric correction of remotely sensed ocean colour (MERIS instrument): Principle and implementation for atmospheres carrying various aerosols including absorbing ones. Int. J. Remote Sens. 1999, 20, 1875-1916. [CrossRef]

19. Antoine, D. Atmospheric Corrections over Case 1 Waters (CWAC) OLCI Level 2 ATBD 2010, v.2.2. S3-L2-SD-03-C07-LOV-ATBD. Available online: https:/ / earth.esa.int/documents/247904/349589/OLCI_ L2_ATBD_Atmospheric_Corrections_case-1_waters.pdf (accessed on 31 October 2016).

20. Ahn, J.H.; Park, Y.J.; Kim, W.; Lee, B. Simple aerosol correction technique based on the spectral relationships of the aerosol multiple-scattering reflectances for atmospheric correction over the oceans. Opt. Express 2016, 24, 29659-29669. [CrossRef] [PubMed]

21. IOCCG. Atmospheric correction for remotely-sensed ocean-colour products. In Reports of International Ocean-Colour Coordinating Group 2010; Wang, M., Ed.; IOCCG: Dartmouth, NS, Canada, 2010.

22. Vermote, E.F.; Tanré, D.; Deuze, J.L.; Herman, M.; Morcette, J.J. Second simulation of the satellite signal in the solar spectrum, 6S: An overview. IEEE Trans. Geosci. Remote Sens. 1997, 35, 675-686. [CrossRef]

23. Kotchenova, S.Y.; Vermote, E.F.; Matarrese, R.; Klemm, F.J., Jr. Validation of a vector version of the $6 S$ radiative transfer code for atmospheric correction of satellite data. Part I: Path radiance. Appl. Opt. 2006, 45, 6762-6774. [CrossRef] [PubMed]

24. Kotchenova, S.Y.; Vermote, E.F. Validation of a vector version of the $6 \mathrm{~S}$ radiative transfer code for atmospheric correction of satellite data. Part II. Homogeneous Lambertian and anisotropic surfaces. Appl. Opt. 2007, 46, 4455-4464. [CrossRef] [PubMed]

25. Franz, B. rhoa_to_rhoas()-MS Aerosol Reflectance to SS Aerosol Reflectance, aerosol.c in SeaDAS Code 2004. Available online: http:/ / seadas.gsfc.nasa.gov (accessed on 31 October 2016). 
26. Wang, M. Correction of artifacts in the SeaWiFS atmospheric correction: Removing discontinuity in the derived products. Remote Sens. Environ. 2003, 84, 603-611. [CrossRef]

27. Ahmad, Z.; Franz, B. Atmospheric correction using multiple-scattering epsilon values. In Proceedings of the Ocean Optics XXII, Portland, MA, USA, 26-31 October 2014.

28. Antoine, D.; Morel, A. Relative importance of multiple scattering by air molecules and aerosols in forming the atmospheric path radiance in the visible and near-infrared parts of the spectrum. Appl. Opt. 1998, 37, 2245-2259. [CrossRef] [PubMed]

29. Morel, A.; Maritorena, S. Bio-optical properties of oceanic waters: A reappraisal. J. Geophys. Res. 2001, 106, 7163-7180. [CrossRef]

30. Siegel, D.A.; Wang, M.; Maritorena, S.; Robinson, W. Atmospheric correction of satellite ocean color imagery: The black pixel assumption. Appl. Opt. 2000, 39, 3582-3591. [CrossRef] [PubMed]

31. Shettle, E.P.; Fenn, R.W. Models for the Aerosols of the Lower Atmosphere and the Effects of Humidity Variations on Their Optical Properties. Air Force Geophysics Lab Hanscom Afb Ma. 1979, No. AFGL-TR-79-0214. Available online: http:/ / www.dtic.mil/docs/citations/ADA085951 (accessed on 17 September 2018).

32. SeaWiFS Reprocessing \#4 (2002)—Case 7: Improved Cloud Flagging Method. Available online: https: / / oceancolor.gsfc.nasa.gov / reprocessing/r2002/seawifs / (accessed on 10 June 2018).

33. O’Reilly, J.E.; Maritorena, S.; Mitchell, B.G.; Siegel, D.A.; Carder, K.L.; Garver, S.A.; Kahru, M.; McClain, C. Ocean color chlorophyll algorithms for SeaWiFS. J. Geophys. Res. 1998, 103, 24937-24953. [CrossRef]

34. Wang, M. Extrapolation of the aerosol reflectance from the near-infrared to the visible: The single-scattering epsilon vs multiple-scattering epsilon method. Int. J. Remote Sens. 2004, 25, 3637-3650. [CrossRef]

35. Ahmad, Z.; Franz, B.A.; McClain, C.R.; Kwiatkowska, E.J.; Werdell, J.; Shettle, E.P.; Holben, B.N. New aerosol models for the retrieval of aerosol optical thickness and normalized water-leaving radiance from the SeaWiFS and MODIS sensors over coastal regions and open oceans. Appl. Opt. 2010, 49, 5545-5560. [CrossRef] [PubMed]

36. Chowdhary, J.; Tsigaridis, K.; Nelson, N. Spaceborne ocean color remote sensing in the UV-A part of the spectrum. In Proceedings of the Ocean Optics XXIV, Dubrovnik, Croatia, 7-12 October 2018.

37. Gordon, H.R.; Wang, M. Surface-roughness considerations for atmospheric correction of ocean color sensor. 2: Error in the retrieved water-leaving radiance. Appl. Opt. 1992, 31, 4261-4267. [CrossRef] [PubMed]

38. André, J.M.; Morel, A. Simulated effects of barometric pressure and ozone content upon the estimate of marine phytoplankton from space. J. Geophys. Res. 1989, 94, 1029-1037. [CrossRef]

39. Tzortziou, M.; Herman, J.R.; Ahmad, Z.; Loughner, C.P.; Abuhassan, N.; Cede, A. Atmospheric $\mathrm{NO}_{2}$ dynamics and impact on ocean color retrievals in urban nearshore regions. J. Geophys. Res. 2014, 119, 3834-3854. [CrossRef]

40. Tzortziou, M.; Parker, O.; Lamb, B.; Herman, J.; Lamsal, L.; Stauffer, R.; Abuhassan, N. Atmospheric Trace Gas $\left(\mathrm{NO}_{2}\right.$ and $\left.\mathrm{O}_{3}\right)$ Variability in South Korean Coastal Waters, and Implications for Remote Sensing of Coastal Ocean Color Dynamics. Remote Sens. 2018, 10, 1587. [CrossRef]

41. Pahlevan, N.; Ahn, J.H. Uncertainty in atmospheric parameters for diurnal remote sensing of coastal oceans. In Proceedings of the Ocean Optics XXIV, Dubrovnik, Croatia, 7-12 October 2018.

42. Wang, M.; Gordon, H.R. Calibration of ocean color scanners: How much error is acceptable in the near infrared? Remote Sens. Eviron. 2002, 82, 497-504. [CrossRef]

43. Franz, B.A.; Bailey, S.W.; Werdell, P.J.; Morel, A.; McClain, C.R. Sensor-independent approach to the vicarious calibration of satellite ocean color radiometry. Appl. Opt. 2007, 46, 5068-5082. [CrossRef] [PubMed]

44. Pahlevan, N.; Roger, J.C.; Ahmad, Z. Revisiting short-wave-infrared (SWIR) bands for atmospheric correction in coastal waters. Opt. Express 2017, 25, 6015-6035. [CrossRef] [PubMed]

45. Wang, M.; Gordon, H.R. Sensor performance requirements for atmospheric correction of satellite ocean color remote sensing. Opt. Express 2018, 26, 7390-7403. [CrossRef] [PubMed]

(C) 2018 by the authors. Licensee MDPI, Basel, Switzerland. This article is an open access article distributed under the terms and conditions of the Creative Commons Attribution (CC BY) license (http:/ / creativecommons.org/licenses/by/4.0/). 